\title{
THE CLINICAL MANIFESTATIONS AND PATHOMECHANICS OF CONTRACTURE OF THE EXTENSOR MECHANISM OF THE KNEE
}

\author{
K. Bose and K. C. Chong, Singapore \\ From the Department of Orthopaedic Surgery, University of Singapore
}

\begin{abstract}
Experience with thirty-eight Asian children and adolescents who presented with either stiffness of the knee, genu recurvatum, habitual dislocation of the patella or congenital lateral dislocation of the patella showed that all those disorders were manifestations of contracture of the extensor mechanism, which fell into two groups according to the components involved. In Group I the main components affected were in the midline of the limb, namely rectus femoris and vastus intermedius; these patients presented with varying degrees of stiffness of the knee, or worse, with genu recurvatum. In Group II the main components involved were lateral to the midline of the limb, namely vastus lateralis and the ilio-tibial band; these patients presented with habitual dislocation of the patella, or worse, congenital lateral dislocation of the patella. In both groups untreated patients developed secondary adaptive changes such as subluxation of the tibia or marked genu valgum which made operative procedures more formidable and less effective. Release of the contracture should therefore be performed as early as possible.
\end{abstract}

Contracture of the quadriceps causing varying degrees of stiffness of the knee has been well documented (Hněvkovský 1961; Gunn 1964; Williams 1968). However, the role of the various components of the extensor mechanism in the pathogenesis of genu recurvatum and of habitual and congenital dislocation of the patella has been controversial. Clinical and operative experience of thirty-eight such patients has brought out several interesting features relating to pathogenesis and classification.

\section{MATERIAL}

Thirty-eight Asian children and adolescents with this type of disorder attended the Singapore General Hospital between 1966 and 1973; contractures secondary to poliomyelitis, arthrogryposis and myelomeningocele were excluded. Twelve patients had bilateral involvement, making a total of fifty knees in the study (Table I). All the patients were reviewed clinically and radiographically. In twenty there was a history of repeated injections into the thigh, but it was seldom possible to ascertain the precise nature of the drug, the dosage or the number of injections; in the other eighteen there was no relevant history. All fifty knees had some type of extensor release, and in six a low femoral osteotomy was necessary to realign the limb.

\section{CLINICAL MANIFESTATIONS OF EXTENSOR CONTRACTURE}

\section{Group I}

Stiffness of the knee-There were seventeen patients, seven of whom were bilateral cases, making a total of twenty-four knees. Flexion movement ranged from 10 degrees to 90 degrees or slightly more (Table II, Figs. 1-3). Their ages ranged from five months to sixteen years, the average being four years. In nine patients there was a definite history of intramuscular injections in the thigh, on average four months before attendance; only two of the nine had bilateral involvement.

Genu recurvatum with various degrees of anterior subluxation of the tibia-There were six patients, three of whom

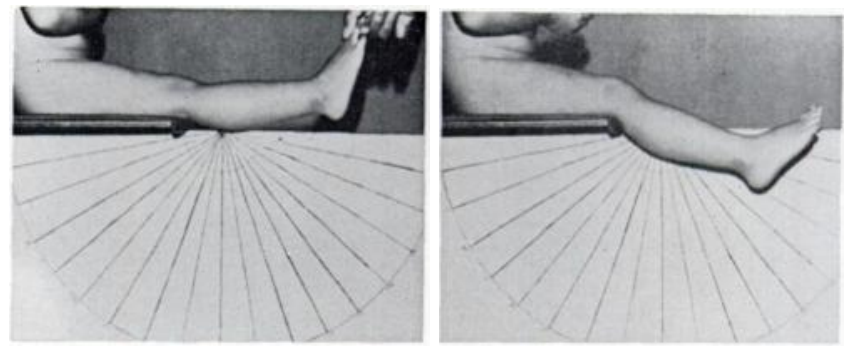

Fig. 1

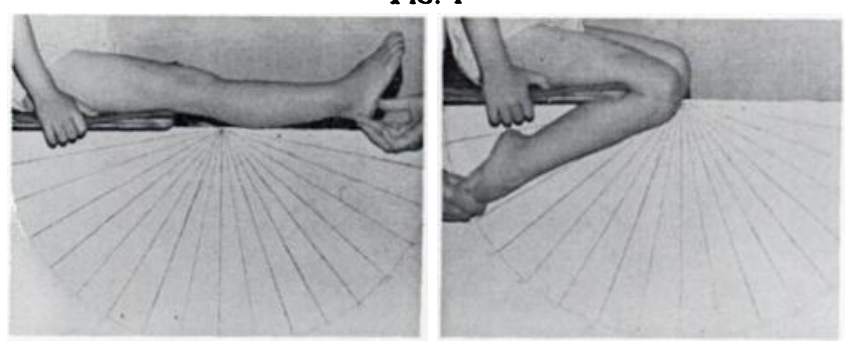

Fig. 2
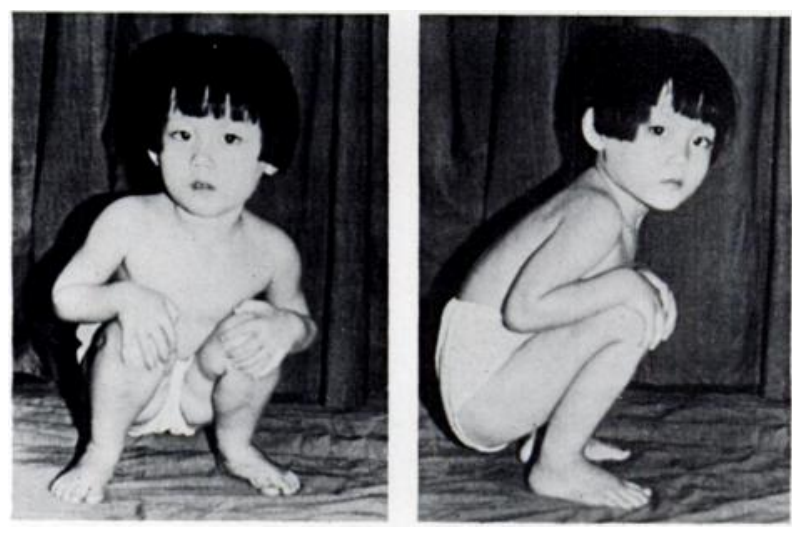

Fig. 3

Stiffness of the knee in a boy aged four (Group I). Figure 1Before operation, range 0 to 30 degrees. Figure 2-After operation, range 0 to 150 degrees. Figure 3-His ability to squat; essential in the East.

had bilateral involvement, making a total of nine knees; their ages ranged from three months to sixteen years, the average being nine years. There was no range of flexion

Dr K. Bose, A.M., M.S., M.Ch.Orth., F.R.C.S.(Ed.) $\}$ University Department of Orthopaedic Surgery, Singapore General Hospital. Dr K. C. Chong, M.Med., F.R.C.S.

Outram Road, Singapore 3, Republic of Singapore. 
TABLE I

Clinical Material

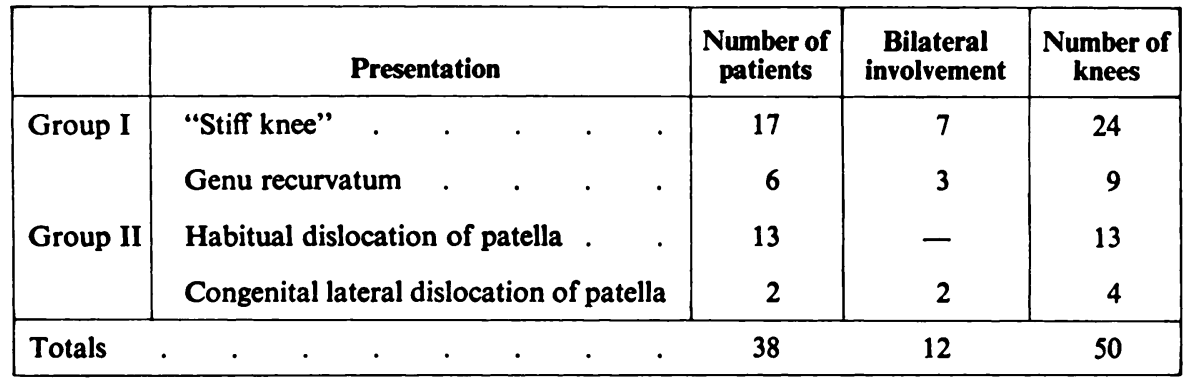

TABLE II

Range of Flexion Movement in Group I Cases before Operation

\begin{tabular}{|c|c|c|c|c|c|c|c|c|c|}
\hline \multirow[b]{2}{*}{ Diagnosis } & \multirow{2}{*}{$\begin{array}{l}\text { Number of } \\
\text { knees }\end{array}$} & \multicolumn{8}{|c|}{ Range of movement } \\
\hline & & 0 to $90+$ & 0 to 90 & 0 to 30 & 0 to 10 & -30 to 0 & -60 to 0 & -90 to 0 & -70 to -30 \\
\hline “Stiff knee" & 24 & 4 & 7 & 8 & 5 & & & & \\
\hline Genu recurvatum & 9 & & & & & 2 & 4 & 1 & 2 \\
\hline
\end{tabular}

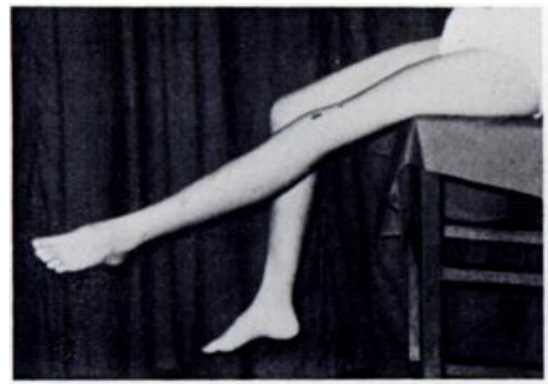

FIG. 4

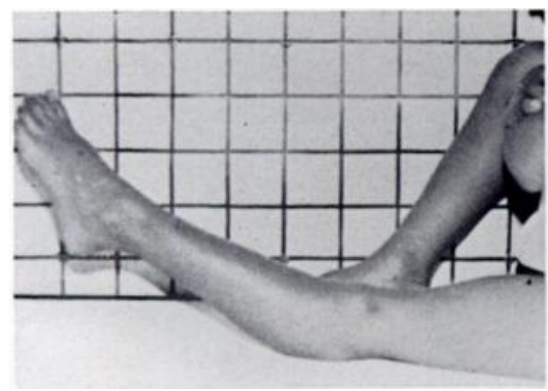

Fig. 7

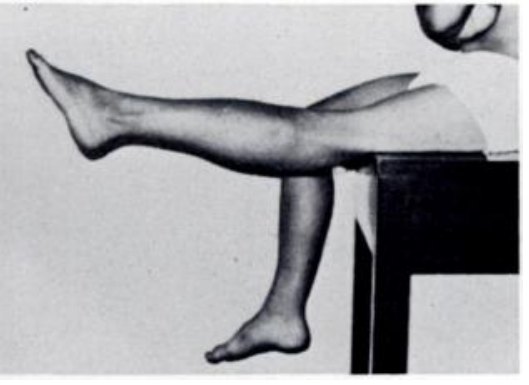

Fig. 5

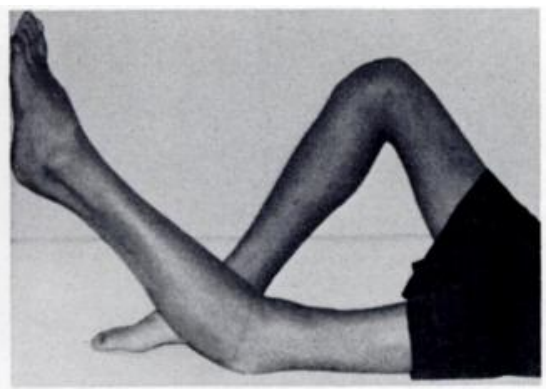

FIG. 8

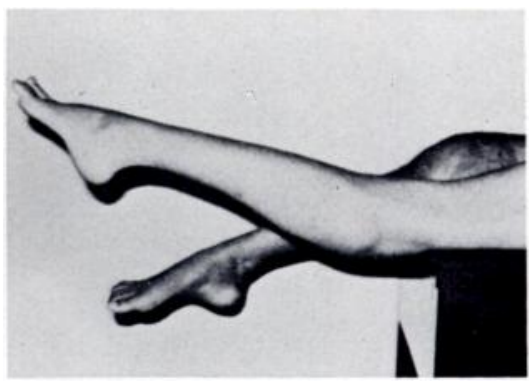

FIG. 6

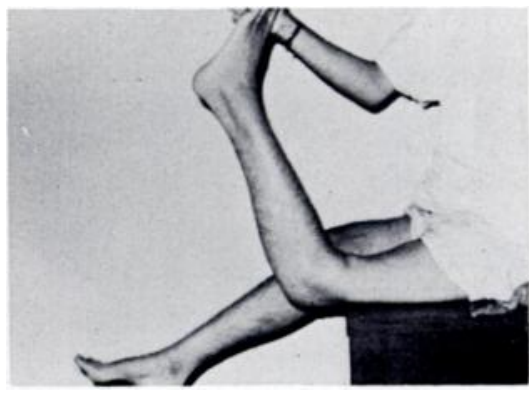

FiG. 9

Six Group I cases in Figure 4-A girl aged ten with only 5 degrees of flexion of the knee. Figure 5-A boy aged fifteen with 5 degrees of recurvatum and no flexion. Figure 6-A girl aged sixteen with 30 degrees of recurvatum and no flexion. Figure 7-A boy aged fourteen with 40 degrees of recurvatum and no flexion. Figure 8-A boy aged sixteen with 50 degrees of recurvatum. Figure $9-A$ girl aged eighteen with 70 degrees of recurvatum.

movement in all nine knees (Figs. 4 to 9). The range of hyperextension movement in two knees was 30 degrees, in four knees up to 60 degrees, and in one knee it was 90 degrees. In one bilateral case the range of hyperextension movement was from 30 degrees to 70 degrees on both sides (Table II). In two patients, both unilateral cases, there was a history of intramuscular injections about eighteen months previously.

\section{Group II}

Habitual dislocation of the patella-There were thirteen patients, all with unilateral involvement; their ages ranged from two to ten years, the average being seven years. The patella dislocated laterally every time the knee was flexed between 20 and 60 degrees (Figs. 10 to 12); the range of flexion in all thirteen knees was full. Nine patients had a history of intramuscular injections into the thigh, all before the age of three years.

Congenital lateral dislocation of the patella with various degrees of lateral subluxation of the tibia and of genu valgum-There were only two patients, both of them bilateral cases; they were three months and three years old respectively when first seen. In all four knees the patella was dislocated in every position of the knee joint, flexion was full and active extension was absent. Neither patient had had any injection in the thigh. 
RADIOLOGICAL APPEARANCES

Group I-In cases of "stiff-knee" the earliest abnormality noted was that the patella, when visible, was smaller and higher on the affected side (Fig. 13). Changes in the lower femoral and upper tibial condyles were noted as early as three years and progressed till maturity (Fig. 14).

Cases of genu recurvatum showed more advanced changes. In the initial period flattening of the lower femoral and upper tibial epiphyses was noted especially on the antero-lateral side, and led on to premature fusion. Weight-bearing accentuated the deformity, the tibia tending to subluxate forwards. In

\section{OPERATIVE PROCEDURES}

These were performed by different surgeons but the technique was fairly uniform.

Group I-For the twenty-four cases of "stiff knee" the quadriceps muscle was explored through a long anterolateral incision. The vastus intermedius was examined and when found to be taut it was divided. If full knee flexion was thus achieved, the wound was closed without

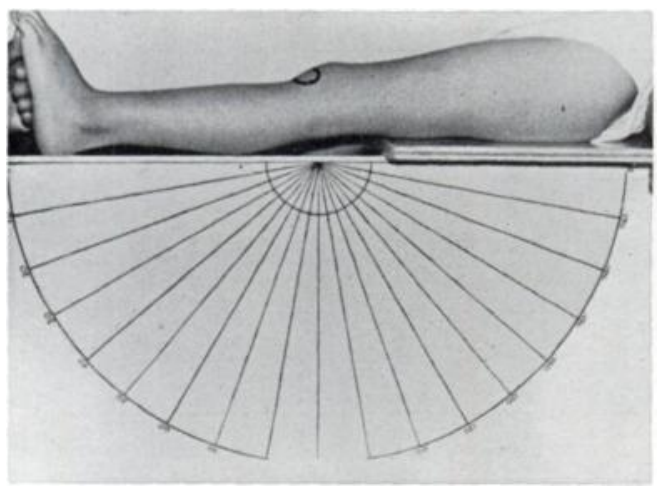

FIG. 10

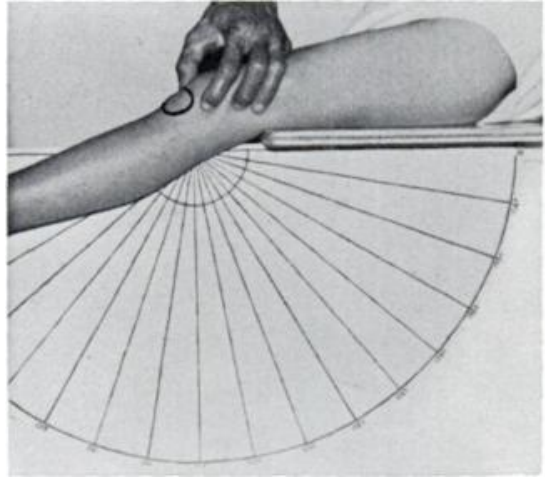

Fig. 11

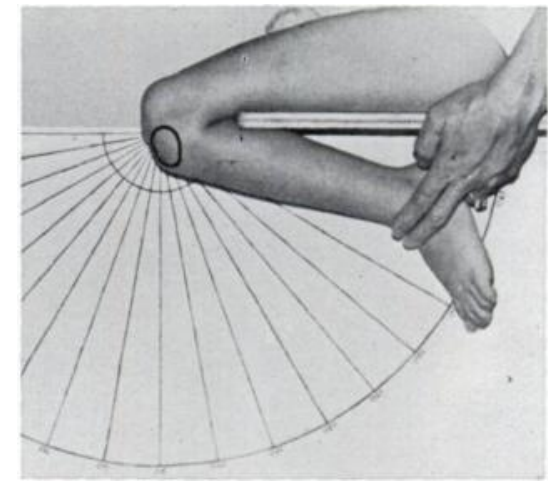

Fig. 12

A boy aged seven with habitual dislocation of the patella (Group II). Figure 10-The patella in position with the knee extended. Figure 11-The knee is unable to be flexed beyond 30 degrees if the patella is held in place. Figure 12-Further flexion possible when the patella with the extensor tendon is allowed to displace laterally.

long-standing cases there were also adaptive changes in the contour of the articular surfaces of femur and tibia (Figs. 15 to 20$)$.

Group II-In cases of habitual dislocation of the patella changes in the femoral and tibial condyles were noted as early as five years. In the initial stages the patella was situated laterally with slight reduction in height of the lateral part of the lower femoral and upper tibial epiphyses, which accentuated any valgus deformity (Figs. 21 to 23) and in long-standing cases led to premature fusion. Hypoplasia of the lateral femoral condyle (Fig. 24) and external torsion of the tibia also occurred in these neglected cases. It is difficult to say whether the hypoplasia was the cause or the effect of dislocation of the quadriceps tendon, but we believe it was a secondary effect for two reasons-it was seen only in the older children, and once the quadriceps had been lengthened and realigned the dislocation did not recur.

In cases of congenital lateral dislocation of the patella the earliest abnormality, noted at three months, was genu valgum. Later the patella was seen to be small, high and lateral, with associated subluxation of the tibia (Fig. 25). any attempt to repair the muscle; otherwise a " $Z$ " lengthening of rectus femoris was also performed. The more significant element impeding flexion was regarded as the main component of the contracture (Table III), though other components of the quadriceps might require division. The main contractures found in this group involved vastus intermedius in ten, rectus femoris in eight, and a combination of rectus femoris, vastus intermedius and vastus lateralis in six knees.

In the nine knees with recurvatum and various degrees of anterior subluxation of the tibia, the main contracture was in rectus femoris in six and in a combination of rectus femoris, vastus intermedius, vastus lateralis and ilio-tibial band in three knees (Table III). In these last three, all long-standing cases, the quadriceps tendons were approached by two separate incisions, antero-medial and antero-lateral. After release of the several contractures the tibial subluxation could easily be reduced, but low fem- 


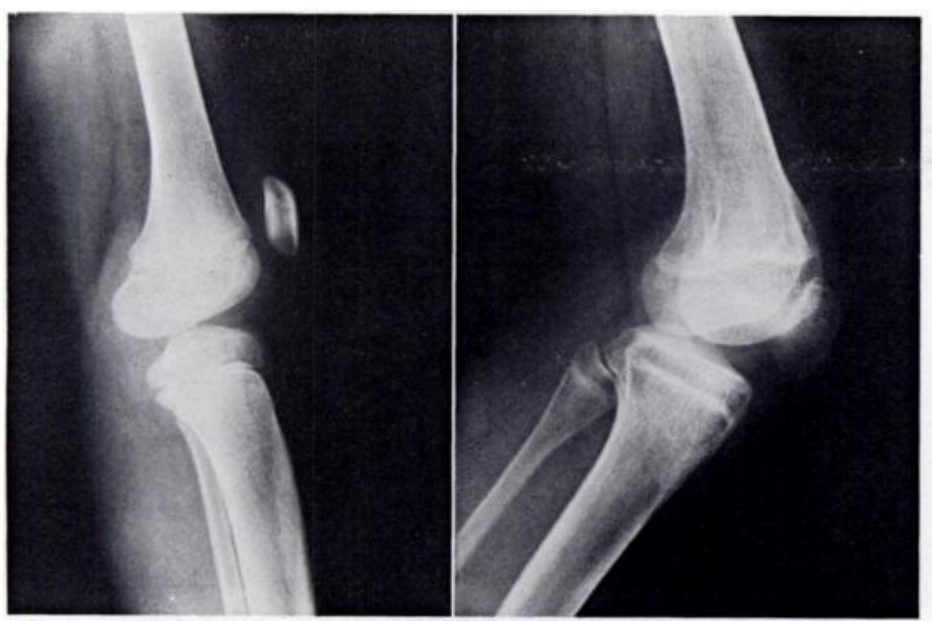

Fig. 13

A girl aged fourteen with stiffness of the knee and only 5 degrees of flexion before quadricepsplasty (left), but 120 degrees after operation (right). Note the change in position of the patella.

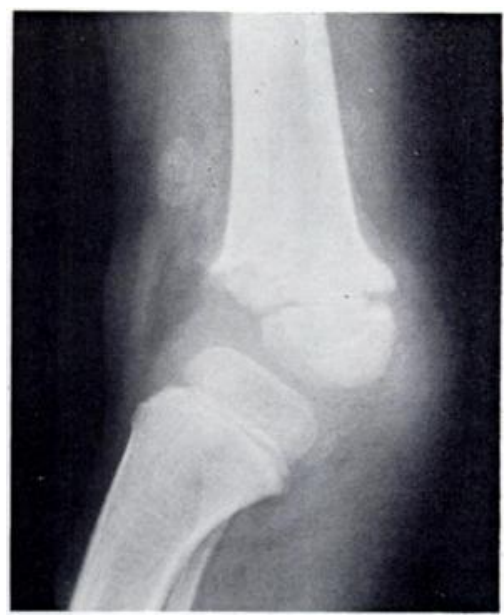

FIg. 14

A boy aged eight with a high patella, anterior subluxation of the tibia and early changes in the femoral and tibial condyles.

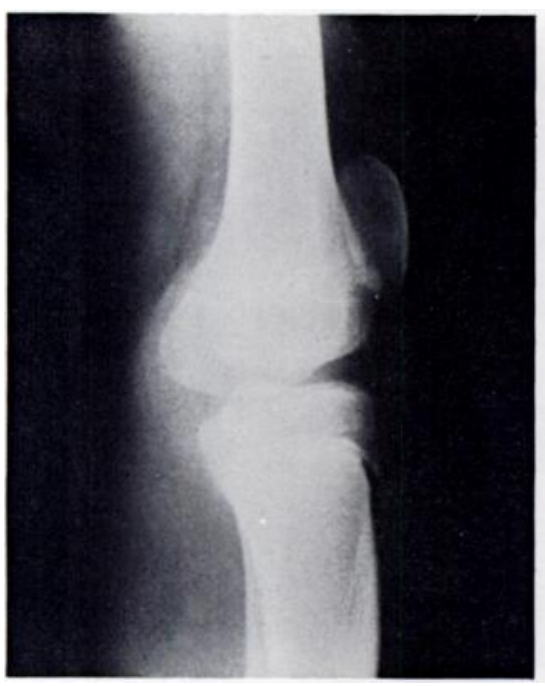

Fig. 15

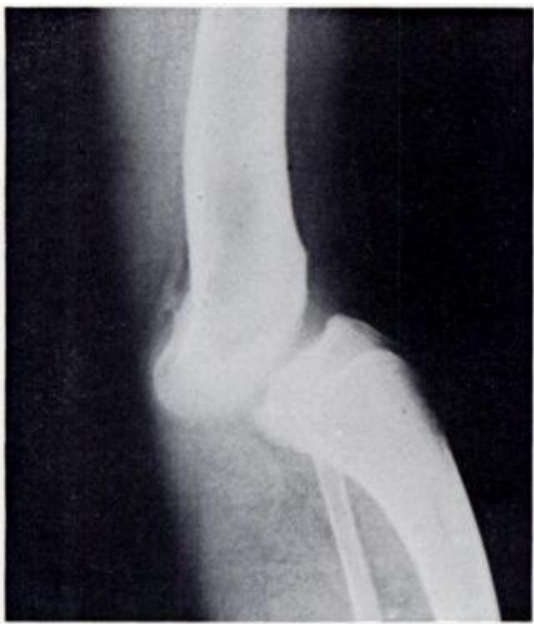

Fig. 18

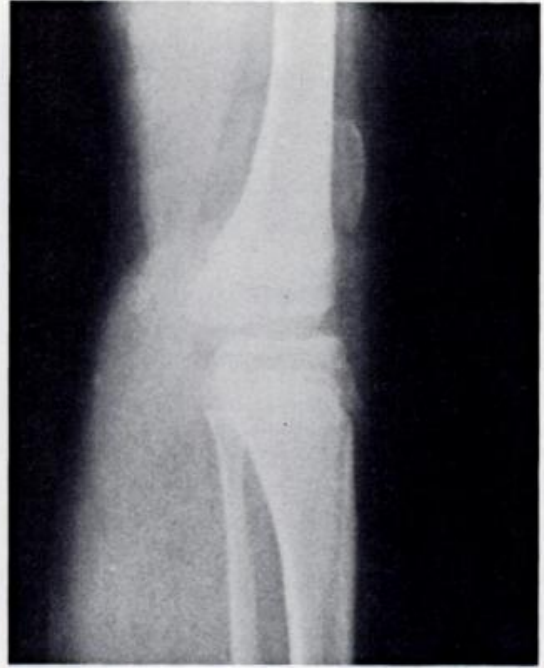

Fig. 16

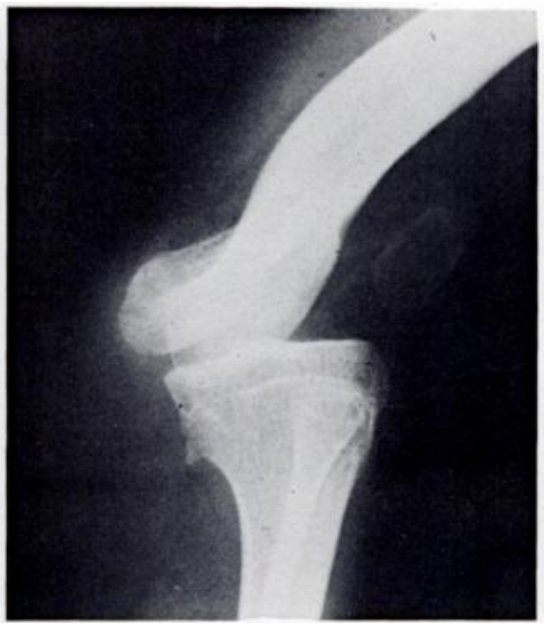

Fig. 19

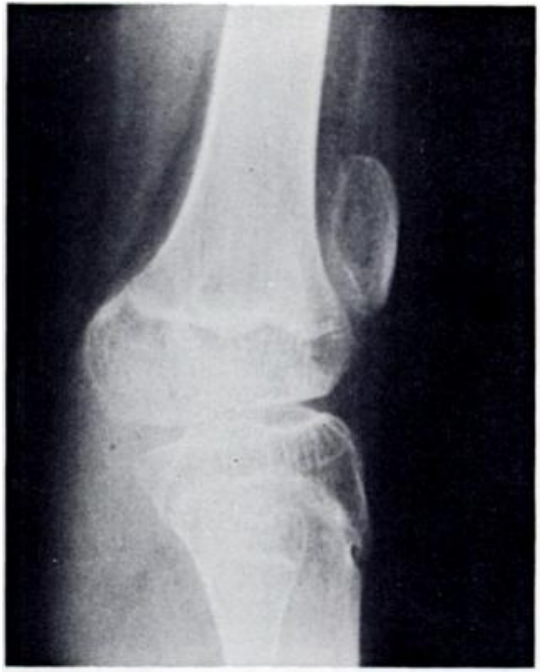

Fig. 17

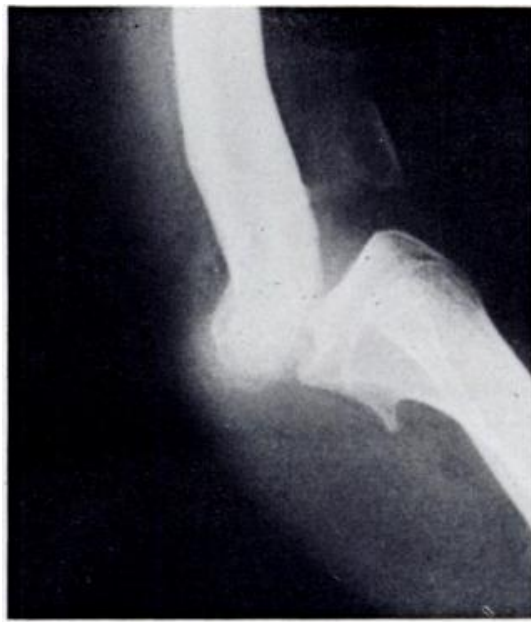

FIG. 20

Group I cases showing epiphysial changes. Figure 15-A girl aged ten with 5 degrees of flexion of the knee. Figure 16-A boy aged twelve with 10 degrees of recurvatum and no flexion. Figure 17-A boy aged fourteen with 20 degrees of recurvatum and no flexion. Figure 18-A boy aged sixteen with 40 degrees of recurvatum. Figure 19-A girl aged eighteen with 60 degrees of recurvatum. Figure 20A girl aged eighteen with 80 degrees of recurvatum. 
oral wedge osteotomy was performed at the same time in order to obtain stability of the knee joint. A posterior wedge of bone was removed so as to permit the necessary degree of rotation of the femoral condyles, and if possible the osteotomy was fixed with a plate and screws (Figs. ilio-tibial band in five, and a combination of ilio-tibial band, vastus lateralis, vastus intermedius and lateral fibres of rectus femoris in two knees (Table III). The contractures were divided transversely, allowing a full range of flexion without dislocation of the patella, and no attempt

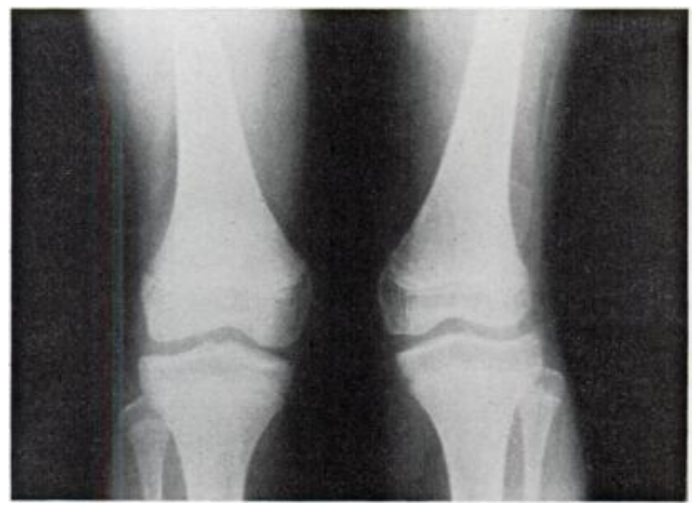

FIG. 21

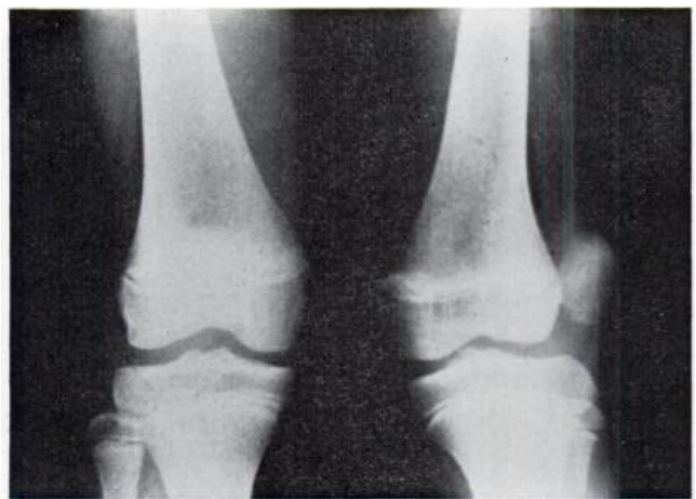

FIG. 22

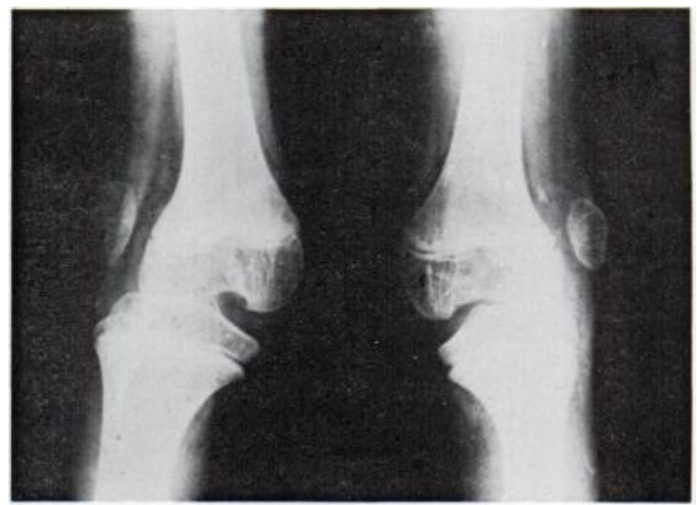

Fig. 23

Cases of habitual dislocation of the patella. Figure $21-\mathbf{A}$ boy aged ten with valgus deformity of the left knee. Figure $22-\mathbf{A}$ girl aged eleven with more marked valgus of the left knee and lateral subluxation of the tibia. Figure $23-A$ girl aged sixteen with gross valgus of both knees and marked lateral subluxation of the tibiae.

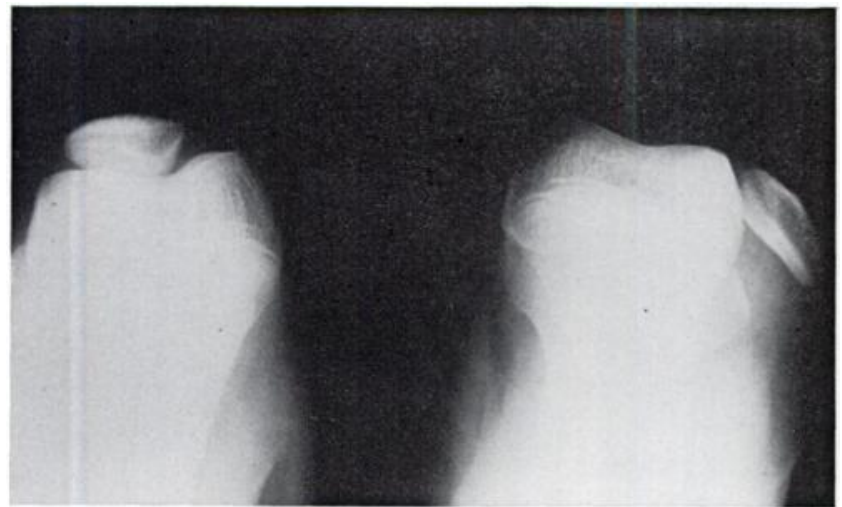

Fig. 24

Showing hypoplasia of the lateral femoral condyle in a boy aged sixteen with habitual dislocation of the left patella.

26 to 27). The knee was then immobilised in a plaster cast for eight weeks.

Group II-In the thirteen cases of habitual dislocation of the patella the quadriceps was again explored through a long antero-lateral incision. The main contractures found in this group were of vastus lateralis in six knees, of the

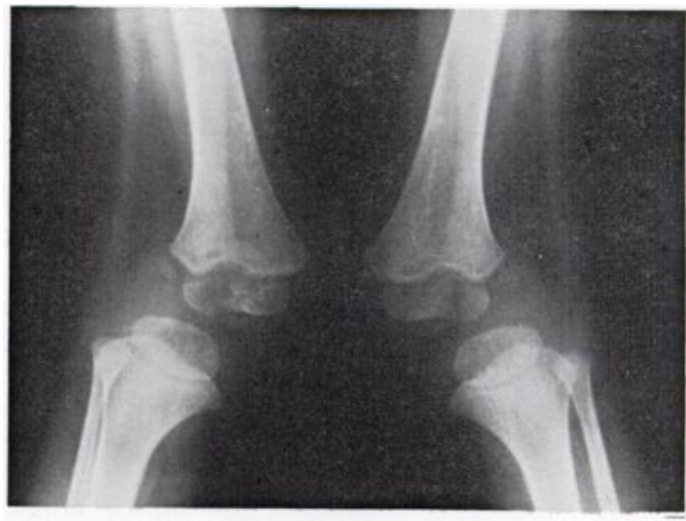

Fig. 25

A girl aged three with congenital lateral dislocation of the patellae, showing lateral subluxation of the tibia and genu valgum on both sides.

was made to repair the defects. Medial plication was then done to give additional stability to the patella. The knees were immobilised in 70 to 90 degrees of flexion for two weeks, after which active movements were commenced.

In two knees with congenital dislocation of the patella, gross genu valgum and lateral subluxation of the tibia, varus supracondylar osteotomy was also performed. 


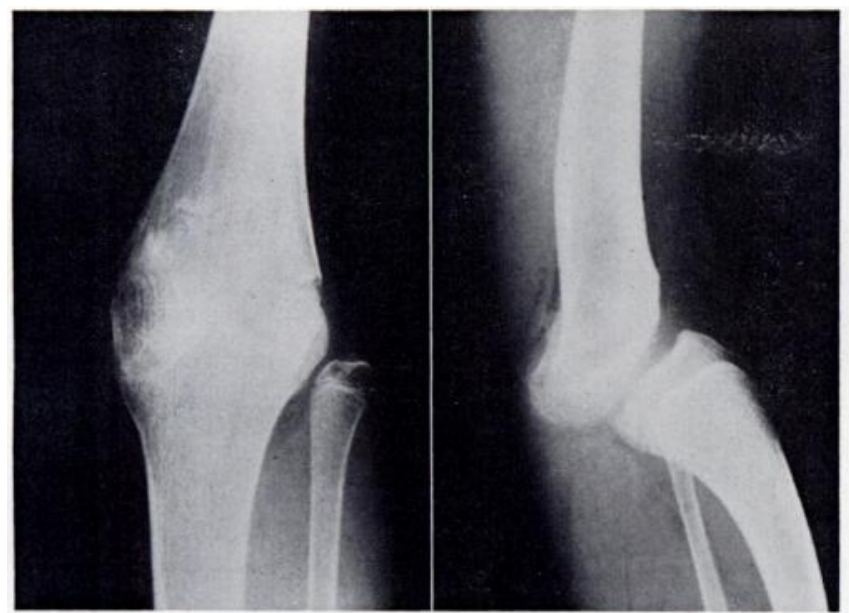

FIG. 26

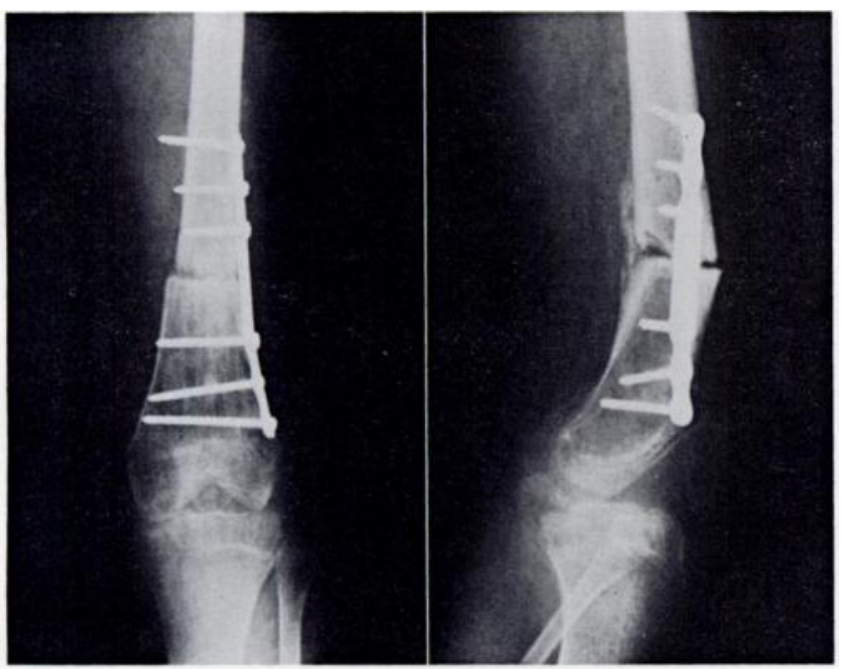

Fig. 27

Radiographs of a girl aged eighteen with severe genu recurvatum and a range of hyperextension from 30 degrees to 80 degrees. After release of the contracture and low femoral osteotomy (Figure 27) the range of flexion was from 0 to $\mathbf{4 0}$ degrees, with 10 degrees of extensor lag.

\section{RESULTS}

In the analysis of the results particular attention was paid to full flexion of the knee because squatting is an essential part of the everyday life of these Asian patients.

Group I-All cases of "stiff knee" achieved active knee flexion beyond 90 degrees, irrespective of age. In ten knees active flexion was more than 120 degrees, in four
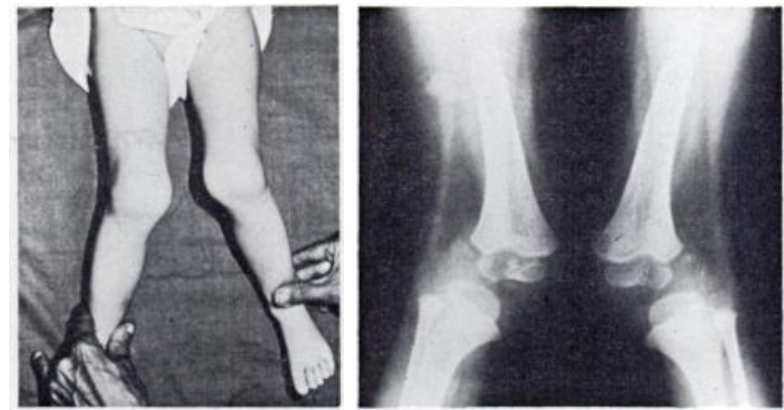

Fig. 28

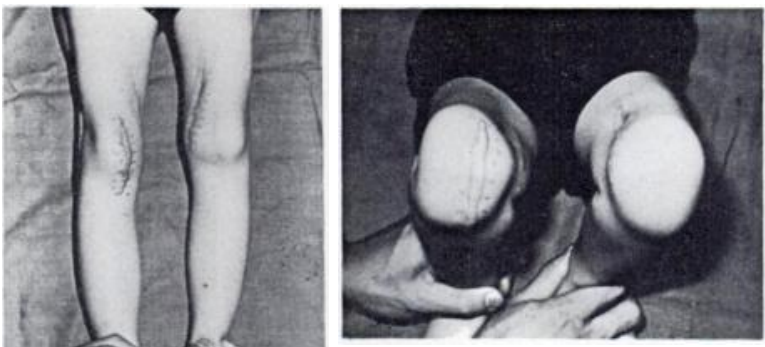

Fig. 29

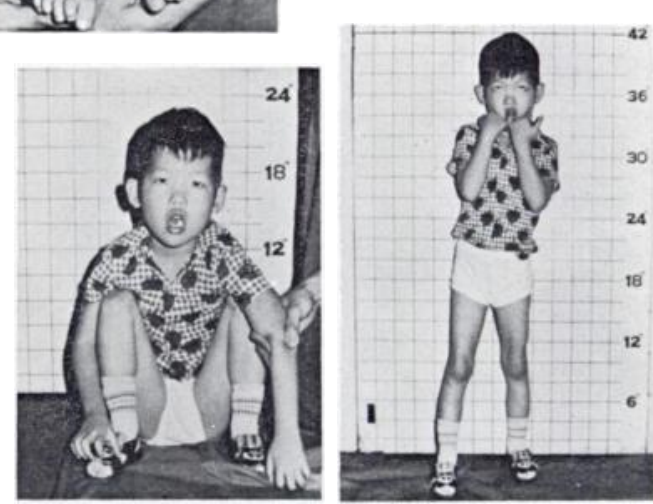

Fig. 30

A case of congenital lateral subluxation of the patellae. Figure 28At the age of three months. Figure 29-Soon after lateral release and medial plication on the medial side to realign the extensor mechanism performed at the age of three months. Figure 30-The result at two and a half years, showing stable knees with full flexicn.

knees between 100 and 120 degrees, and in three knees between 90 and 100 degrees. The older children, especially those over five years, had a smaller range of flexion and a persistent extensor lag varying from 10 to 30 degrees even as long as three years after the operation. In two cases the operation had to be repeated after six and nine months respectively because of inadequate release of the contracture.

TABLE III

Site of Main Contracture in Groups I AND II

\begin{tabular}{|c|c|c|c|c|c|c|c|}
\hline & Presentation & $\begin{array}{c}\text { Number of } \\
\text { knees }\end{array}$ & $\begin{array}{c}\text { Rectus } \\
\text { femoris }\end{array}$ & $\begin{array}{c}\text { Vastus } \\
\text { intermedius }\end{array}$ & $\begin{array}{c}\text { Vastus } \\
\text { lateralis }\end{array}$ & $\begin{array}{c}\text { Ilio-tibial } \\
\text { band }\end{array}$ & Combined \\
\hline \multirow{2}{*}{ Group I } & "Stiff knee" . . . & 24 & 8 & 10 & - & - & 6 \\
\hline & Genu recurvatum & 9 & 6 & - & - & - & 3 \\
\hline \multirow{2}{*}{ Group II } & Recurrent dislocation of patella . & 13 & - & - & 6 & 5 & 2 \\
\hline & Congenital lateral dislocation of patella & 4 & - & - & 2 & 1 & 1 \\
\hline
\end{tabular}


In cases of genu recurvatum with various degrees of anterior subluxation of the tibia, the range of knee flexion after operation varied from 30 to 120 degrees. Only two patients, who were one and three years old at the time of operation, achieved more than 120 degrees of flexion without extensor lag. One patient with bilateral involvement who was five years old at the time of operation achieved 110 and 120 degrees of flexion on the right and left sides respectively, but an extensor lag of 30 degrees on both sides persisted even after another five years. Three older children aged thirteen, sixteen and seventeen had only 20 to 40 degrees of active flexion with an extensor lag varying from 10 to 30 degrees. Though the flexion gained in these older patients was not remarkable, the recurvatum was corrected, the gait was considerably improved and the knees were stable. It is felt that for best results the patient should be operated upon below the age of five years; in older children secondary changes develop in the capsule, ligaments and cartilage of the joint, all of which vitiate the end-result. Again, operation is far simpler in a young child; simple division of the contracted band may then be quite adequate.

Group II-In cases of habitual dislocation of the patella, all knees but one could be flexed beyond 120 degrees without dislocation of the patella, irrespective of age. In a single case flexion was limited to 90 degrees even after the operation had been repeated. Both the cases of congenital lateral dislocation of the patella with lateral subluxation of the tibia achieved a full range of flexion and stable knees (Figs. 28 to 30 ).

At follow-up no patient in either group had any symptom or radiological change suggestive of chondromalacia of the patella or osteoarthritis of the knee.

\section{DISCUSSION}

The pathomechanics of quadriceps contracture have received little attention in the literature, although some aspects of the aetiology (Gunn 1964), clinical features (Williams 1968) and treatment (Hněvkovský 1961 ; Karlen 1964) have been well documented. From the operative findings in the present series, cases of contracture of the extensor mechanism can be divided into two groups as we have already indicated: 1) those in the line of the limb; and 2) those lateral to that line.

In Group I cases the presentation varies according to the severity of the contracture and the age of the patient. In milder cases there will only be some degree of stiffness of the knee, whereas in cases of severe contracture developing before or just after birth the child will have genu recurvatum. If the stiffness is not relieved, secondary adaptive changes may occur as early as five years and eventually lead to anterior subluxation of the tibia.

Similarly in Group II cases the manifestations vary. In a normal knee the stability of the patella depends to some extent on the relative prominence of the lateral femoral condyle and on the lower oblique fibres of vastus medialis (Last 1963). With full knee flexion the normal quadriceps tendon has an excursion of two to three centimetres. In these cases of contracture the involvement is more pronounced laterally and there is loss of excursion of the quadriceps tendon. Thus the natural tendency to lateral drift of the patella with flexion of the knee is considerably accentuated, and with some loss of the range of normal excursion the quadriceps tendon has to slip over the lateral condyle for full flexion to be achieved. The antero-lateral pull of the patellar tendon can lead to lateral subluxation and external rotation of the tibia (Figs. 21 to 23). In milder cases there is only habitual dislocation of the patella, but in cases of contracture presumably arising before birth, the child presents with congenital dislocation of the patella and lateral subluxation of the tibia (Fig. 25). The factors that have been mentioned as contributing to recurrent dislocation of patella, namely high patella (Dickson 1936), or genu valgum with lateral rotation of the tibia and poor development of the lateral condyle (Smillie 1951), are in fact secondary effects.

It is interesting to note that the clinical manifestation keeps to its own group; thus a stiff knee may lead to genu recurvatum but not to lateral subluxation of the patella. This has been observed by other authors (Williams 1968).

Our thanks are due to orthopaedic surgeons both in Government Service and in the University Unit for allowing us to review their cases. We would like to thank Associate Professor P. B. Chacha for valuable criticism and advice. Miss Joanna Lam for secretarial help and Mr S. H. Tow, A.R.P.S., for the photography.

\section{REFERENCES}

Dickson, J. A. (1936) Recurrent dislocation of the patella. Surgical Clinics of North America, 16, 997-1000. Gunn, D. R. (1964) Contracture of the quadriceps muscle. Journal of Bone and Joint Surgery, 46-B, 492-497.

Hněvkovský, O. (1961) Progressive fibrosis of the vastus intermedius muscle in children. Journal of Bone and Joint Surgery, 43-B, 318-325. Karlen, A. (1964) Congenital fibrosis of the vastus intermedius muscle. Journal of Bone and Joint Surgery, 46-B, 488-491.

Last, R. J. (1963) Anatomy: Regional and Applied. Third edition, p. 203. London: J. \& A. Churchill Ltd.

Smillie, I. S. (1951) Injuries of the Knee Joint. Second edition, p. 249. Edinburgh: E. \& S. Livingstone Ltd.

Williams, P. F. (1968) Quadriceps contracture. Journal of Bone and Joint Surgery, 50-B, 278-284. 